\title{
O SISTEMA DE SOLUÇÃo DE CONTROVÉRSIAS DA ORGANIZAÇÃO MUNDIAL DO COMÉRCIO*
}

\author{
Celso Lafer \\ Professor Titular da Faculdade de Direito da USP \\ Embaixador-Chefe da Missão Permanente do Brasil em Genebra junto à ONU e à OMC \\ Presidente (1966) do Órgão de Solução de Controvérsias da OMC ${ }^{* *}$
}

\section{$-\mathrm{A}$}

I

Introdução: Comércio, Direito e Paz

No plano internacional, um tema central é a dicotomia guerra/paz. Daí a importância da reflexão em torno de como se evitar a guerra e de que maneira criar condições para uma humanidade pacífica.

\section{(i) Comércio}

No âmbito desta significativa e importante reflexão, recorrendo à "lição dos clássicos" e para introduzir um primeiro aspecto do tema desta "Conferência Gilberto Amado" cabe lembrar a importância atribuída ao comércio internacional como uma das condições para uma humanidade pacífica.

Montesquieu, por exemplo, fala na relevância do doux commerce para amainar o ímpeto dos preconceitos e promover uma interdependência positiva entre as Nações. ${ }^{1}$

Kant, no Projeto de Paz Perpétua, aponta que uma das suas garantias é o "espírito do comércio que não pode coexistir com a guerra" ${ }^{2}$

* In memoriam: Prof. Hernert W. Briggs.

** Versão em português, revista e ampliada, da Conferência pronunciada em inglês, em Genebra, na Comissão de Direito Internacional da ONU em 18 de junho de 1996, na série das Gilberto Amado Memorial Lectures. As informações estão atualizadas até 26 de julho de 1996.

1. Montesquieu, De L'Esprit des Lois, cronologia, introdução, bibliografia por Victor Goldschmidt, Paris, GF-Flammarion, 1979 XX, 1/XX, 2 pp. 9-10 também cf. Claude Morilhat Montesquieu, Politique et Richesses, Paris : PUF, 1996. 
Esta visão positiva da relação entre comércio e paz está na origem do projeto da International Trade Organization e da Carta de Havana - e do seu desdobramento - o GATT que, com base no sucesso da Rodada Uruguai, levou à Organização Mundial do Comércio.

Decisivos no segundo pós-guerra na modelação da ordem econômica mundial, os Estados Unidos seguiram a linha da avaliação já feita nos anos 30 pelo Secretário de Estado, Cordel Hull, que afirmava: I have never faltered and I will never falter on my belief that enduring peace and the welfare of nations are indissolubly connected with friendliness, fairness, equality and the maximum practible degree of freedom in international trade. ${ }^{3}$ Em síntese: the freeing of international trade from tariff and other restrictions as the prerequisite to peace and economic development, nas palavras de Dean Acheson, ${ }^{4}$ avaliando a policy de C. Hull.

O término do conflito Leste-Oeste, a queda do Muro de Berlim que o antecede em emblematiza, ampliaram e praticamente universalizaram a aceitação axiológica desta visão de humanidade pacífica por meio do comércio que, em síntese, assevera que a prosperidade das nações não é possível em isolamento autárquico. Só pode ser efetivamente alcançada pela interdependência econômica. Esta requer e comporta um sistema multilateral de comércio, lastreado na racionalidade da reciprocidade dos interesses, apto a reger a cooperação e o conflito entre distintas economias nacionais num mercado globalizado.

A OMC é a grande expressão do aprofundamento e alargamento da lógica da globalização econômica pós-Guerra Fria. Esta lógica exprime-se, em primeiro lugar, pela nova abrangência ratione-personae dos membros da OMC: países desenvolvidos, em desenvolvimento, antigos países socialistas em transição para uma economia de mercado. Lembre-se, neste sentido, que o GATT no seu momento inicial era integrado por 23 partes-contratantes e à Marrakesh, quando se criou a OMC, compareceram 123 Estados. Daí, diga-se de passagem, para completa

2. Eternal Peace, in The Philosophy of Kant, editado com introd. De Carl J. Friedrich, New York, Modern Library, 1977 , p. 455 . A referência é a primeira adição aos artigos do Projeto de Paz Perpétua.

3. Economic Barries to Peace. N.Y., W. Wilson Foundation, 1937, p. 14 - citado in K. Dam, The GATT-Law and International Economic Organization, Chicago, The University of Chicago Press, 1970, p. 12.

4. Present at the Creation, N. Y., Norton, 1969, p. 9. 
e efetiva universalização da OMC, dimensão política do acesso da Rússia e da China.

A globalização espelha-se, também, na amplitude ratione-materiae dos assuntos de que trata e disciplina a OMC, em contraste com o GATT. Este, na prática, cuidava do comércio internacional de bens industrializados; tinha poucas regras e muitas exceções. A OMC contempla, também, inter dia, agricultura, serviços, propriedade intelectual e caracteriza-se por muitas regras e poucas exceções. As Rodadas do GATT envolviam negócios e cifras da ordem de: US\$ 4.9 bilhões na Rodada Dillon (Genebra, 1960-1961, 45 países), US $\$ 40$ bilhões na Rodada Kennedy (Genebra, 1964-1967, 49 países), US\$ 155 bilhões na Rodada Tóquio (Genebra 1973-1979, 98 países). Em contraste, o universo econômico que resultou na criação da OMC (Rodada Uruguai, Genebra, 1986-1994), em negociações de que participaram mais de 120 países, tem um affected trade estimado em US\$ 3.7 trilhões. $^{5}$

\section{(ii) Direito}

O Direito é uma técnica de organização social importante para a paz. Daí a idéia da paz pelo Direito, como outro ingrediente importante da reflexão sobre uma humanidade pacífica, que remonta, para novamente lembrar a lição dos clássicos, à tradição de Grócio.

Law is an order of security, that is of peace, diz Kelsen e mesmo que não se possa dizer, como ele aponta na $2^{\mathrm{a}}$ edição de The Pure Theory of Law, alterando a que dissera em General Theory of Law and State, that the state of law is necessarily a state of peace and that the securing of peace is an essential function of law não há dúvida, nas palavras do próprio Kelsen, que the development of law runs in this direction. ${ }^{6}$

No plano internacional, uma das técnicas de viabilizar a paz, como limite ideal para o qual o Direito tende, é solução pacífica de controvérsias.

No Direito Internacional Público geral e contemporâneo -, tal como positivado pela Carta das Nações Unidas, art. $2^{\circ}$, $3^{\circ}$ - a solução pacífica de

5. Cf. John H. Jackson, William J. Davey, Alan O. Sykes, Legal Problems of International Economic Relations, $3^{\mathrm{a}}$ ed., St. Paul, Minn., West Publishing Co., 1995, p. 314.

6. Hans Kelsen, The Pure Theory, trad. da $2^{\mathrm{a}}$ ed. (rev. e ampl.), ed. alemã por Max Knight, Berkeley e Los Angeles, University of Califomia Press, 1967, p. 38. 
controvérsias é, como aponta Bruno Simma, uma "obrigação de conduta" dos Estados, cabendo ressalvar que não é uma obrigação de resultados. Esta "obrigação de comportamento" é vista como parte integrante indispensável para levar a Friendly relations and cooperation among states in accordance with the Charter of the United Nations para lembrar a conhecida Resolução da Assembléia Geral da ONU de $1970 .^{7}$

O art. 33, $\S 1^{\circ}$ - da Carta da ONU elenca estes meios, e a Declaração de Manila de 1982 da Assembléia Geral sobre Solução Pacífica de Controvérsias (G.A. Resolution 37/10), que retoma a Declaração de 1970 sobre Friendly relations, observa que as partes escolherão os meios pacíficos apropriados em função das circunstâncias e da natureza da controvérsia. Como é sabido, estes meios, estas técnicas voltadas para a convivência pacífica, são negociação, inquérito, mediação, conciliação, arbitragem, solução judicial, que se diferenciam pelo grau de controle que as partes retêm, ou não, sobre o encaminhamento da solução de uma controvérsia. $^{8}$

Na Gilberto Amado Memorial Lecture de 1993, o professor Lucius Caflisch examinou as novas tendências em matéria de solução de controvérsias, mas exclui de sua análise os métodos empregados nos campos dos direitos humanos, das tarifas e comércio e da integração regional política e econômica. ${ }^{9}$

É justamente uma das áreas que ele excluiu, tariffs and trade, a que vou examinar nesta conferência, na qual me proponho analisar a relação entre comércio internacional e solução pacífica de controvérsias, tal como foi previsto e está sendo praticado no âmbito da OMC.

7. Cf. The Charter of the United Nations - A Commentary, ed. por Bruno Simma, Oxford, Oxford University Press, 1955, p. 99; Fábio K. Comparato, Obrigações de Meios, de Resultados, de Garantia, Revista dos Tribunais, v. 353 (1965), pp. 14-6.

8. Cf. The Charter of the United Nations - A Commentary, ed. por Bruno Simma, cit., pp. 506-12; J. G. Merrils, International dispute Settlement ( $2^{\mathrm{a}}$ ed.), Cambridge, Cambridge University Press, 1993.

9. Lucius Caflisch, New Trends on Peaceful Settlement of Disputes, Geneva, United Nations, 1993, p. 3. 


\section{A Comissão de Direito Internacional da ONU e Gilberto Amado: codificação e desenvolvimento progressivo do Direito Internacional relação com a temática desta Conferência}

A relação entre a CDI, a figura de Gilberto Amado e o tema da conferência, que tem o seu nome, precisa, no entanto, ser preliminarmente apontada.

Gilberto Amado participou da criação da CDI e da redação do seu estatuto, como foi lembrado pelo professor Cançado Trindade na sua conferência de 1987. A CDI tem como tarefa a promoção do desenvolvimento progressivo do Direito Internacional e a sua codificação (estatuto da CDI, art. $1^{\circ}$ ).

$\mathrm{O}$ art. 15, de cuja redação Gilberto Amado também participou ativamente, como lembrou igualmente o professor Cançado Trindade, e que trata das funções da CDI, estabelece for convenience uma distinção entre codification and progressive development. As duas expressões, entendia Gilberto Amado, no entanto, deveriam go together - pois não são departamentos estanques. ${ }^{10}$ Há, observo, entre "codificação" e "desenvolvimento progressivo", uma dialética de mútua complementaridade. Toda codificação implica em desenvolvimento progressivo e todo desenvolvimento progressivo implica em codificação. Este é o caso, como se verá, do sistema de solução de controvérsias da OMC, que é ao mesmo tempo uma codificação e um desenvolvimento progressivo do sistema do GATT.

Na sua conferência de 1987, sobre a personalidade de Gilberto Amado, o Embaixador Sette Câmara, que antes de ter sido Juiz da Corte Internacional de Justiça foi membro da CDI, registrou que ainda mais do que nos seus livros, o melhor de Gilberto Amado estava na sabedoria de seus comentários. ${ }^{11}$

No importante livro de Herbert W. Briggs, The International Law Commission antigo membro da CDI, onde foi colega de Gilberto Amado, cuja memória e excepcionais qualidades de jurista aproveito, como seu ex-aluno em Cornell, para homenagear com reverente admiração recolho dois comentários de Gilberto Amado.

10. Cf. A.A. Cançado Trindade, La Contribution de Gilberto Amado aux Travaux de la Commission de Droit International, Genève, Nations Unies, 1988, pp. 18-9.

11. José Sette Câmara, Cent Ans de Plénitude, Gèneve, Nations Unies, 1988, pp. 12-3. 
A CDI, dizia Gilberto Amado, deve evitar o risco de ser a body of jurists shut up in an ivory tower, pois the work of codification, like that of development of international law, must be carried out in cooperation with the political authorities of States. ${ }^{12}$

É minha intenção comprovar, nesta conferência, que estas sábias indicações de Gilberto Amado estão presentes no sistema de solução de controvérsias da OMC.

\section{B}

\section{Comércio Internacional e Solução Pacífica de Controvérsias Observações Gerais}

Para um exame apropriado do sistema de solução de controvérsias da OMC, é importante também, antes, fazer algumas considerações, macro de natureza política e econômica -, sobre comércio e direito.

Uma das dimensões da lógica da globalização e do que significou, no plano dos valores, a queda do Muro de Berlim que são dados fundamentais para a compreensão do pano-de-fundo que permitiu o sucesso da Rodada Uruguai e a criação da OMC foi uma significativa atenuação dos conflitos de concepção, a respeito da organização da economia mundial. A expressão conflitos de concepção tem uma hierarquia analítica distinta da de conflitos de interesses que basicamente giram em torno de uma avaliação do que um país está ganhando ou perdendo, em termos econômicos, numa determinada situação, e como se pode remediar um problema deste tipo. Com efeito, conflitos de concepção colocam-se não apenas no campo econômico mas também no campo dos valores. São mais difusos pois, além dos interesses específicos, dizem respeito a convergências ou divergências profundas a respeito do funcionamento da sociedade, da política, da economia.

No período da Guerra-Fria, o sistema internacional regia-se por polaridades definidas Leste-Oeste; Norte-Sul. A conseqüência das polaridades definidas, no campo econômico mundial, eram visões distintas do modelo ideal de organização econômica.

12. Herbert W. Briggs, The International Law Commission, Ithaca, New York, Comell University Press, p. 30. 
Assim, por exemplo, a visão da URSS era a do dirigismo econômico e, por tabela, o de um comércio administrado por metas quantitativas, tal como se expressava no COMECOM.

Já a visão do Grupo dos 77 era a de buscar uma "nova ordem econômica internacional" que resultaria de "negociações globais" de alcance redistributivo. A UNCTAD, quando foi criada, e nos seus desdobramentos, buscou responder a esta visão Norte-Sul de uma renovação da organização da economia mundial.

A OMC representou, com a sua criação, algo novo, inerente ao mundo pós-Guerra Fria e à lógica da globalização: a aceitação praticamente erga omnes de uma visão gattiana ampliada GATT plus - de organização da economia mundial.

Esta universalização de uma visão, cuja pujança e hegemonia econômica era indiscutível - (pujança que resultava da abertura do espaço interestatal, por vários tipos de mecanismos, a uma circulação bastante livre de recursos como mercadorias, serviços, tecnologia, investimentos, num processo conduzido pelos Estados e por atores privados e estimulado pelos descobrimentos técnicos que reduziam o tempo e o custo dos transportes e das comunicações) se traduziu, no campo econômico, para recorrer a uma fórmula de Raymond Aron, à passagem de um sistema internacional heterogêneo (de valores contrapostos) para um sistema internacional homogêneo, de uma visão compartilhada. ${ }^{13}$

Este é um dado básico a explicar porque e como se conseguiu negociar um sistema multilateral de comércio rule oriented, de vocação universal. Com efeito, esta nova homogeneidade, permitiu que se afirmasse, com a $\mathrm{OMC}$, para recorrer à "lição dos clássicos": uma leitura grociana da convivência econômica internacional. ${ }^{14}$ Em poucas palavras: existe um potencial de sociabilidade que permite uma interação organizada - e não-anárquica - entre os protagonistas da vida econômica num mercado globalizado, que não funciona como um jogo de "somazero" Existe confronto, mas existe também cooperação, baseada num abrangente processo calcado na racionalidade e na funcionalidade da reciprocidade dos

\footnotetext{
14. Cf. Hedley Bull, The Importance of Grotius in the Study of International Relations, in Hugh Grotius and International Relations, ed. Hedley Bull, Benedict Kingsburg, Adam Roberts, Oxford, Clarendon Press, 1992, pp. 65-93; Celso Lafer, Brasil y el Nuevo Escenario Mundial, Archives del Presente, 3 - Vernano-Austral, 95-96, pp. 61-80.
} p. 108.

13. Cf. Raymond Aron, Paix et Guerre entre les Nations, $3^{\text {a }}$ ed. rev., Paris, Calmann-Lévy, 1962, 
interesses. Daí o papel positivo que podem desempenhar o sistema jurídico do Direito Internacional Público e as organizações internacionais.

Esta interação organizada, entre uma multiplicidade de economias nacionais, requer um mecanismo de interface, inclusive porque o comércio entre os países tem como uma de suas bases as diferenças de vantagens comparativas entre as economias. Como observa Jackson, numa muito apropriada metáfora, as relações entre as economias nacionais, num mercado globalizado, envolvem um problema análogo ao das dificuldades de fazer trabalhar em conjunto computers of different designs. Isto exige um interface mechanism de mediação. A OMC é este mecanismo. $^{15}$

Este mecanismo é fundamental porque o mercado nunca é "perfeito" e não-opera no vazio. Requer uma moldura jurídica que exprime realidades políticas e econômicas. Além disso, se o mercado e a competição podem ser vistas como uma luta de todos por todos - é a tese do doux commerce - é também, simultaneamente, como aponta com sutileza Simmel a luta de todos contra todos. ${ }^{16}$

A idéia diretiva da OMC é a de que a gestão desta relação, de conflito e cooperação, deve ser um jogo que tem normas, compartilhadas por todos que dele participam e vistas por todos como as de um fair play.

Foi nesse sentido que Peter Sutherland observou que o patrimônio da OMC não são recursos como é o caso do Banco Mundial, e num certo sentido o do FMI. São a credibilidade, a aceitabilidade e a observância de suas normas.

A interpretação destas regras à luz da lógica da experiência jurídica nunca é inequívoca ou unívoca por obra das dificuldades epistemológicas inerentes ao estabelecimento da relação entre o fato e o direito. Com efeito, os elementos da conexão da operação de qualificação jurídica dos fatos comportam tanto o concurso quanto o conflito de qualificações, ensejando-se, neste processo de subsunção, mais de uma possibilidade de avaliação do fato, do direito e da relação entre os dois. Os Estados, por isso mesmo, diferem no seu entendimento, a respeito do alcance e da aplicação das normas do Direito Internacional e buscam, quando lhes cabe proceder,

15. Jonh H. Jackson, The World Trading System, Cambridge, Mass., the MIT Press, 1992, p. 218.

16. Cf. Albert O. Hirschman, Rival Views of Market Societies and Other Recent Essays, Cambridge, Mass., Harvard University Press, 1992, pp. 120-1. 
unilateralmente, ao processo de qualificação a conduzí-lo em função da legitimação política plena de sua conduta e dos seus interesses. ${ }^{17}$

É precisamente para evitar o unilateralismo político da interpretação e conter o self help na sua aplicação por meio de "retorsões" e "represálias comerciais" que o sistema multilateral de solução de controvérsias da OMC foi concebido, enquanto um mecanismo rule oriented, na linha grociana, destinado a "domesticar" as tendências unilaterais das "razões de estado" power oriented. É este, explicitamente, o sentido e os compromissos assumidos no âmbito da OMC, ex vi do art. 23 da "Understanding on Rules and Procedures Governing the Settlement of Disputes" (DSU).

Os contenciosos da diplomacia econômica que a OMC busca encaminhar, como foi dito, e neste sentido a organização é tributária da tradição do GATT, dizem respeito basicamente a conflitos de interesse. Com efeito, o GATT como modelo de cooperação organizada, sustentava-se na idéia da reciprocidade de interesses, e na sua manutenção no tempo. Daí o art. XXIII do GATT, que continua sendo a pedra angular da OMC, nesta matéria, posto que os conflitos derivam de percepção de uma parte-contratante de que qualquer benefit accruing to it directly or indirectly under this Agreement is being nullified or impaired.

O sistema de solução de controvérsias do GATT resultou da prática de suas partes-contratantes, em relação ao art. XXIII, que por sua vez foram codificadas e objeto de desenvolvimento progressivo, em mais de uma oportunidade. Foi com base no lastro desta experiência, e na sua melhoria, que se negociou o sistema da OMC. O art. XXIII tem uma conexão muito grande com o art. XXII, pois ambos compõem a base e a lógica do sistema.

Assim cabe uma explicitação de obrigação geral de consultar, prevista no art. XXII do GATT, que continua sendo, com o art. XXIII no sistema da OMC, o eixo do processo de solução de controvérsias, como está afirmado no art. $3^{\circ}$, $\S 1^{\circ}$ - do "Understanding on Rules and Procedures Governing the Settlement of Disputes" (DSU).

17. Cf. Jean J. A. Salmon, Quelques observations sur la qualification en Droit International Public, in La Motivation des Decisions de Justice, estudos publicados por Ch. Perelman e Paul Foriers, Bruxelles, Bruylant, 1978, pp. 345-65. 


\section{A "obrigação de consultar" como técnica do Direito Internacional Econômico - seu papel no sistema GATT/OMC}

O GATT contempla, no seu art. XXII, uma obrigação de comportamento Each contracting party shall accord sympathetic consideration to, and shall afford adequate opportunity for consultation regarding such representations as many be made by another contracting party with respect to any matter affecting the operating of this Agreement (art. XXII-1).

A obrigação de consultar está presente em inúmeros outros artigos do GATT (art. II-5; VI-7; VII-1; VIII-2; IX-6; XII-4; XVI-1; XVIII-7, 12, 16, 21, 11; XIX, 2; XXIV-7; XXV,1; XXVIII; XXVIII-1, 4; XXXVII, 2), que tratam de matérias específicas por exemplo, valoração aduaneira, marcas de origem, balança de pagamentos, subsídios, retirada de concessões tarifárias, etc.

Qual é a razão destas obrigações de consultar, enquanto obrigações de comportamento?

A vida econômica no mercado caracteriza-se pela conjuntura e pelo aleatório, que podem alterar a reciprocidade dos interesses - sobretudo porque se trata de uma reciprocidade derivada da equivalência das vantagens e não da identidade das trocas. Refiro-me aqui à dinâmica das vantagens comparativas e outros aspectos tratados pela teoria econômica do comércio internacional. Por este motivo, como aponta Prosper Weil, a consulta no Direito Internacional Econômico é uma técnica tanto da elaboração quanto da aplicação de normas. ${ }^{18} \mathrm{~A}$ consulta, na elaboração do direito, leva freqüentemente a normas que têm mais a característica de um standard jurídico do que o da tipificação rígida das condutas posto que a tipificação não-capta a mutabilidade da vida econômica. O standard, por sua vez, pela sua própria natureza, quando aplicado à matéria econômica, enseja mais uma "jurisprudência de interesses" do que uma "jurisprudência de conceitos"

18. Prosper Weil, Le Droit International Economique - myte ou réalité, in Société Française pour le Droit International, Aspects du Droit International Economique élaboration, contrôle, sanction, Paris, Pedone, 1972, p. 73; cf. André Hauriou, Le Droit administratif de l'aléatoire, in Mélanges Trotabas, Paris, Librairie Générale de Droit et de Jurisprudence, 1970, pp. 197-225; Celso Lafer, $O$ Convênio do Café de 1970 da Reciprocidade no Direito Internacional Econômico, São Paulo, Perspectiva, 1979. 
Com efeito, o standard, no momento de sua aplicação, é uma "medida de comportamento", que sempre requer uma verificação, no contexto da especificidade variável das circunstâncias, da reasonableness e fairness da conduta. $^{19}$

As consultas atendem a este requisito. São sempre uma oportunidade para as partes embasarem as avaliações jurídicas de suas posições através de um processo de intelligence gathering, na dupla acepção que a palavra intelligence comporta: a da organização e seleção de informações pertinentes e a da possibilidade de aprender o relevante, para a compreensão de uma situação que está ensejando um potencial contencioso econômico.

As consultas são, assim, no Direito Internacional Econômico, em primeiro lugar, uma ocasião para fact finding, - representam uma forma estruturada de inquérito conjunto, que pode levar, pela negociação, à conciliação dos interesses.

A prática do GATT, em matéria de consultas, inclusive na sistemática do art. XXIII obedece a esta lógica, de "solução pacífica de controvérsias" que atende a especificidade dos contenciosos econômicos. Ela continua presente na OMC, pois como se lê no art. $3^{\circ}, \S 7^{\circ}$ do DSU, "a solution mutually acceptable to the parties to a dispute and consistent with the covered agreement is clearly to be preferred" que por isso mesmo, para instigá-las, viu adensada a juridicidade dos procedimentos de consultas, mediante dispositivos que a tornam automática, obrigatória e sujeita a prazos quando formalmente solicitada por qualquer membro (cf. DSU, art. $4^{\circ}$ ). Nem sempre, no entanto, os múltiplos procedimentos de consulta contemplados pelo GATT, e agora pela OMC, permitem resolver o problema. Daí o sistema derivado do art. XXIII que, no entanto, é permeado por estas considerações sobre a natureza e a especificidade das controvérsias econômicas.

\section{O sistema de solução de controvérsias do GATT - o artigo XXIII}

O sistema de solução de controvérsias do GATT, centrado no art. XXIII, tendo como foco "conflitos de interesses" resultantes de nullification and

19. Cf. Stéphane Rials, Les Standards, Notions Critiques du Droit, pp. 39-53; Jean J. A. Salmon, Les Notions à Contenu Variable en Droit International Public, pp. 251-268; in Les Notions à Contenue Variable en Droit, Estudos publicados por Ch. Perelman e Raymond Vander Eslt, Bruxelles, Bruylant, 1984. 
impairment of benefits é fruto de uma prática. Resulta de um processo que foi evoluindo e sendo objeto de codificação e desenvolvimento progressivo que assumiram a forma de Understandings; Agreed description of costumary practices of the GATT in the field of Dispute Settlement (art. XXIII-2); Ministerial declarations das partes contratantes; decision on dispute settlement; decision on improvement of GATT dispute settlements; decision on procedures under article XXIII. ${ }^{20}$ Estas "formas" que se iniciam em 1966 e se estendem até 1989, representam uma interpretação consensual do GATT, por suas partes contratantes, nos termos do art. $31, \S 3^{\circ}$ (a) da Convenção de Viena sobre o Direito dos Tratados. Não são assim, para relembrar Gilberto Amado, obra de juristas numa torre de marfim, mas inequivocamente uma expressão da sensibilidade dos atores governamentais e da percepção de suas necessidades.

Isto se explica, inclusive, porque todo o sistema do GATT, como hoje o da OMC, é um sistema intergovernamental de Direito Internacional Público Econômico. Só as partes-contratantes tem locus standi e conduzem o processo. Os interesses privados - sempre muito presentes posto que de mercado é o que se trata só alcançavam o GATT quando um governo entendia que havia "interesse nacional" em patrociná-los. Neste sentido operava mutatis mutandis, adaptados a natureza das controvérsias econômicas do comércio internacional, os mecanismos clássicos de proteção diplomática.

Em síntese: codificação e desenvolvimento progressivo do sistema de solução de controvérsias foi o resultado, no GATT, de uma interpretação formalizada pelas partes-contratantes, baseado na prática e no seu aprimoramento, que não tinha base legal explícita no Acordo Geral. ${ }^{21}$ A criativa evolução desta prática, num sentido amplo, indica a passagem com marchas e contramarchas de um sistema mais voltado para a conciliação, como era usual nos acordos de produtos primários, por exemplo café (o que Hudek denominou de "jurisprudência diplomática", ou seja um blen of legal and diplomatic strategies $),{ }^{22}$ para um sistema

20. Cf. GATT Analytical Index: Guide to GATT Law and Practive, 6th ed., 1994, pp. 586-97.

21. Pierre Pescatore - Drafting and Analyzing Decisions on Dispute Settlement, re-impressão do Handbook of WTO/GATT Dispute Settlement, ed. by Pierre Pescatore, William J. Davey e Andreas F. Lowenfeld, New York, Transnational Publishers, Inc., 1995, p. 29.

22. Robert E. Hudek - The GATT Legal System and World Trade Diplomacy, New York, Praeger, 1975, Pref - p. VI; Robert E. Hudek - El sistema del GATT: Jurisprudencia Diplomática, Derecho de Integración, 8 abril, 1971, pp. 34-66; Celso Lafer, O Convênio Internacional do Café, Revista de Direito Mercantil, n. 9, XII, 1973, pp. 48-55. 
que foi abrindo a possibilidade de um adensamento crescente da "juridicidade" na solução de controvérsias, sem nunca excluir a conciliação negociada dos interesses.

A razão desta evolução está ligada à "segurança das expectativas" necessária para o bom funcionamento de um sistema multilateral de comércio. Nas palavras da "Decisão de 1989" sobre o aprimoramento do sistema de solução de controvérsias do GATT: A 1 Contracting parties recognize that the dispute settlement system of GATT serves to preserve the rights and obligations of contracting parties under the General Agreement and to clarify the existing provisions of the General Agreement. It is a central element in providing security and predictability to the multilateral trade system. ${ }^{23}$

Quais são, em linhas gerais, os pontos mais importantes do sistema do GATT?

A competência para o processo de solução de controvérsias, nos termos do art. XXIII-2 cabia, às Partes-Contratantes, agindo em conjunto, que, quando suscitadas, deveriam promptly investigate any matter so referred to them and shall make appropriate recommendations to the contracting-parties which they consider to be concerned, or give a ruling on the matter as appropriate.

No exercício destes quasi-judicial powers, como as qualifica Olivier Long $^{24}$ as Partes-Contratantes - depois de uma fase inicial em que recorreram a working parties - passaram, nos anos cinqüenta, a recorrer a panels independentes. Foi no funcionamento destes panels que residiu a originalidade do sistema do GATT.

A função de um panel é a de review the facts of a case and the applicability of GATT provisions and to arrive at an objective assessment of these matters. ${ }^{25}$ Qual é a natureza jurídica de um panel?

Os panels, usualmente compostos de três membros, não eram (e continuam não-sendo) um tribunal arbitral pelas seguintes razões, apontadas por Pierre Pescatore:

(i) seus membros não eram escolhidos pelas partes. Eram propostos pelo Secretariado. As partes usualmente concordavam, após consultadas com o

23. GATT Analytical Index, cit., p. 592.

24. Olivier Long, Law and its Limitations in the GATT Multilateral Trade System, Dordrecht, Nijhoff, 1987, p. 84.

25. Agreed Description of Customary Practice of the GATT in the Field of Dispute Settlement (Art. XXIII:2) in GATT Analytical Index, cit, p. 589. 
Secretariado. Na inexistência de acordo podiam ser indicados pelo Diretor-Geral. Nacionais das partes envolvidas não deveriam integrá-los e sempre se chamavam "peritos". como tais entendidos membros de delegações do GATT familiarizados com os assuntos e percebidos como "neutros" em relação à controvérsia e depois, no correr do tempo, acadêmicos com formação jurídica e/ou em comércio internacional. (ii) não existia um "compromis" que fixasse ad hoc a competência do panel. Esta resultava usualmente dos standards terms of reference que basicamente estipulava que o assunto, objeto de controvérsia, deveria ser examinado in the light of relevant GATT provisions. ${ }^{26}$

(iii) os findings, recommendations, rulings dos panels não constituíam uma sentença arbitral. Só adquiriam força jurídica mediante sua adoção, por consenso, das PartesContratantes reunidas numa sessão formal do Conselho. São enquanto tal um parecer, ou como diria Bobbio, um conselho dotado de vis directiva, e não um comando com vis cogendi; ${ }^{27}$ conselho cujo cumprimento requeria o consenso do destinatário no caso as Partes-Contratantes, que tinham ex vi do art. XXIII os quasi-judicial powers. Precisamente porque são conselhos e não-comandos, os panel reports são, nas palavras de Pescatore, persuasive not descriptive documents. ${ }^{28}$

O panel, no sistema do GATT, representou portanto, em primeiro lugar, uma instância independente - uma third-party - um tertius. Este tertius não se coloca entre as partes como na mediação ou na conciliação. Coloca-se entre e acima das partes, não por delegação, como na arbitragem, mas de forma autorizada pelo sistema, como um juiz, numa solução judicial. ${ }^{29}$ Entretanto, em contraste com a arbitragem e a solução judicial, não dá uma sentença mas um parecer. A inclusão do tertius, de maneira institucionalizada, despolitizava a situação e o processo de qualificação jurídica dos fatos. Transformava a tensão que é difusa uma controvérsia, que é um desacordo entre Estados um conflito de interesses - que tem um objeto suficientemente circunscrito para se prestar a pretensões claras, suscetíveis de uma apreciação por meio da racionalidade de técnicas jurídicas. ${ }^{30}$

26. Cf. Pierre Pescatore, Drafting and Analyzing Decisions on Dispute Settlement, cit., pp. 11-4.

27. Cf. Norberto Bobbio - Study per una Teoria Generale del Diritto, Torino, Giappichelli, 1970, pp. 49-78.

28. Pierre Pescatore - Drafting and Analizing Decisions on Dispute Settlement, cit., p. 17.

29. Cf. Norberto Bobbio - Il Terzo Assente, Milano, Sonda, 1989, p. 222.

30. Cf. Charles de Visscher, Théories et Réalités en Droit International Public, $4^{\text {eme }}$ ed., Paris, Pedone, 1970, p. 371. 
A atividade do panel, como toda forma de conduta, inclusive a de aconselhar, pode ser objeto de regulamentação jurídica. A prática do GATT, a sua codificação e desenvolvimento progressivo, em matéria de panels, representa um esforço de se chegar a um "parecer" através de um due process jurídico - com prazos, primeiras written submissions das partes e oral hearings, segundo set of submissions e segundo hearings. Normalmente nos oral hearings, o Panel formulava questões sobre matéria de fato e de direito suscitadas nas razões e contra-razões das partes, solicitava documentos e provas e, evidentemente, as partes tomavam conhecimento de seus respectivos argumentos, neste processo de contraditório. Existia, igualmente, espaço para terceiros - third-parties que tivessem indicado o seu interesse - apresentar, por escrito e oralmente, os seus argumentos ao Panel.

O "parecer" do Panel, ainda que vazado, como foi dito acima, pela retórica da persuasão, buscava a forma de uma sentença: a descrição dos fatos, os argumentos das partes e uma conclusão motivada por considerações jurídicas.

A edição de 1994 do GATT Analytical Index contabiliza 195 cases e 81 reports adotados pelas Partes-Contratantes ${ }^{31}$ e o Professor Jackson, em lista atualizada até 1989 que inclui cases que não levaram a panels, elenca 233 cases. $^{32}$

O Professor Hudek - em análise da maior importância - que cobre o período de 1948-1989, contabiliza 207 reclamações. Destas, 64 foram equacionadas (settled or validity otherwise conceded) sem legal ruling; 55 abandonadas ou retiradas sem solução. Das 207 reclamações (complaints), 88, ou seja $43 \%$, led to a ruling of some sort; destas 88 , em 68 casos, ou seja, $77 \%$ o panel concluiu pela procedência da reclamação; destes 68 casos, 60 , ou seja $90 \%$ ended with a positive outcome; 37 (55\%) com full satisfaction of the legal claim; $8(12 \%)$ com a remoção da medida, mas independentemente do legal ruling; 15 (22\%) com partial satisfaction of the legal claim. ${ }^{33}$

Como se verifica, é não-só positivo, mas numericamente relevante, o corpus das soluções encontradas pelo mecanismo do GATT. John H. Jackson observa que o número de casos encaminhados através do sistema do GATT supera e muito - os da Corte Internacional de Justiça (próximo dos 100) e aponta que muitos

31. GATT Analytical Index, cit., pp. 719-34.

32. John H. Jackson, William J. Davey, Alan O. Skyes, Legal Problems of International Economic Relations, cit., p. 331.

33. Cf. Robert Hudek, Daniel L. M. Kennedy, Mark Sgarbossa A Statistical Profile of GATT Dispute Settlemente Cases - Minnesota J. Global of Trade, v. 2:1, 1993, pp. 3-4, 8-10. 
dos casos do GATT "have had as profound consequences on national governments and world affairs as have International Court of Justice cases". ${ }^{34}$

Quais eram, no entanto, as limitações do sistema e por que foi ele objeto de um desenvolvimento progressivo no correr das negociações da Rodada Uruguai que levaram à criação da OMC?

Para os que entendiam que o sistema do art. XXIII era essencialmente uma extensão da "obrigação de consultar" do art. XXII, e que o objetivo do mecanismo de solução de controvérsias era menos o de se chegar a uma solução jurídica, do que se valer do direito para superar diplomaticamente um problema comercial, o que se vislumbrava era um aprimoramento do due process dos procedimentos dos panels e, por tabela, da qualidade da vis directiva dos seus pareceres.

Outros, no entanto, apontavam que como os quasi-judicial powers residiam no Conselho de Representantes das Partes Contratantes, qualquer estado acusado de wrong-doing ensejador de nullification and impairment, tinha poder político para bloquear o funcionamento do sistema. Podia bloqueá-lo impedindo, unilateralmente, o estabelecimento de um panel e, mesmo quando concordasse com o estabelecimento do panel e participasse dos seus procedimentos, podia bloquear a adoção do seu report (the acceptance of the panel's findings and recommendations). ${ }^{35}$

Foi justamente para superar estas dificuldades num sistema internacional que a lógica da globalização tornou mais homogêneo e viabilizou, assim, uma leitura grociana ampliada ratione personae e ratione materiae da convivência econômica internacional para relembrar o que já foi apontado nesta conferência, que se chegou, nas negociações da Rodada Uruguai, ao sistema de solução de Controvérsias da OMC.

Este é assim, explicitamente, como diz o art. $3^{\circ}$ do DSU, uma reafirmação da importância da experiência acumulada do GATT ( $\$ 1^{\circ}$ - codificação-) com um reforço (desenvolvimento progressivo) do componente de segurança e

34. John H. Jackson, Reflections on International Economic Law, University of Pennsylvania Journal of International Economic Law, v. 17, n. 1 (Spring 1966), pp. 18-9; Cf. também Shabtai Rosanne, The Worl Court - What it is and how it works ( $5^{\mathrm{a}}$ ed. rev.), Dordrecht, Hijhoff, 1995, caps. VI e VII.

35. Cf. John Cromme, Reshaping the World Trading System, Geneva, World Trade Organization, 1995, pp. 148-9. 
previsibilidade das expectativas. Este reforço foi tido como grocianamente necessário para o bom funcionamento da ordem do mercado mundial, que como qualquer mercado (como já foi apontado) não-opera no vazio. Requer uma moldura jurídica, suplementada por técnicas jurídicas na dinâmica de sua aplicação, aptas a preservar direitos e obrigações dos membros, negociados nos covered agreements ( $\S$ $\left.2^{\circ}\right)$.

VI O sistema de solução de controvérsias da OMC - continuidade e mudança

(i) A primeira observação a ser feita sobre o sistema de solução de controvérsias da $\mathrm{OMC}$, é a de que, enquanto expressão de codificação e desenvolvimento progressivo e em contraste com o sistema do GATT, não é mero fruto de prática e interpretação. É uma obrigação, de outra hierarquia jurídica, posto que contemplada pelo próprio tratado constitutivo da OMC e enquanto tal, obriga a todos os estados-membros e deve ser cumprida de boa-fé (cf. Convenção de Viena sobre o Direito dos Tratados art. 26). Em outras palavras, é parte do quadro constitutivo de uma nova organização ela própria dotada de subjetividade internacional especializada, distinta da de seus membros o que não acontecia com o GATT que era de natureza contratual. Com efeito, ex vi do art. II do Acordo de Marrakesh que trata do objeto e alcance da OMC o anexo 2, que é o "Dispute Settlement Understanding". é parte integrante dos compromissos dos Estados-membros.

O DSU, por força do seu art. $3^{\circ}, \S 1^{\circ}$ como já foi dito, afirma a continuidade em relação ao sistema do GATT. Deve ser lido em conjugação com o art. XVI, $\S 1^{\circ}$ do Acordo de Marrakesh que afirma que "except as otherwise provided" (desenvolvimento progressivo) a OMC "shall be guided by the decisions, procedures and costumary practices followed by the Contracting Parties to GATT 1947 and the bodies established in the framework of GATT 1947". Por isso, o corpus das decisões do antigo GATT constituem jurisprudência válida para o sistema da OMC e como tal vem sendo citadas pelos novos panels e pelo Órgão de Apelação.

(ii) A segunda observação a ser feita é no sentido de apontar que o "Dispute Settlement Understanding", para fazer frente ao risco de fragmentação, trazido pela 
dispersão dos diversos Códigos da Rodada Tóquio - cada um tendo o seu sistema próprio, o que ensejava o "forum-shopping" representou a criação de um sistema único da OMC. Esta cobre todos os acordos da Rodada Uruguai (cf. art. II, 2 do Acordo de Marrakesh, e "Appendix 1 do Understanding"). Isto significa não-só as novas obrigações assumidas em relação a temas tradicionais da GATT (1947) como por exemplo balança de pagamentos, uniões aduaneiras, zonas de livrecomércio, waivers, medidas fito-sanitárias, barreiras-técnicas ao comércio, dumping, valoração aduaneira, subsídios e countervailing measures etc; mas também temas tradicionais finalmente abrangidos pela OMC, como agricultura, têxteis e mais expressivamente temas novos como TRIMS (medidas de investimentos relacionadas ao comércio), GATS (serviços) e TRIPS (propriedade intelectual). Isto configura, como observou Pescatore, uma nova e mais ampla dimensão de competência, dada pela automacidade do standard terms of reference que abrange all covered agreements citados pelas partes perante um panel (DSU art. $7^{\circ}$ ). ${ }^{36}$ Daí um novo desafio, como aponta Christopher Thomas, pois os panels enfrentarão não-só as clássicas core-obligations do GATT mas less familiar rights and obligations in the new areas of intellectual property, services, etc., com todas as consequiências que daí advêm, inclusive em matéria de provas e qualificação jurídica dos fatos. ${ }^{37}$

(iii) Do ponto de vista do adensamento da "juridicidade" do sistema de solução de controvérsias da OMC, um dado novo, fundamental, a impedir e superar o "bloqueio" unilateral do seu funcionamento, foi a fórmula concebida em 1991, durante as negociações da Rodada Uruguai em Genebra, com base nas opções apresentadas na malograda reunião de Bruxelas. Refiro-me à inversão da regra de consenso, prevalescente no GATT. Nas palavras de Croome: "Where as consensus had been required in order to move the dispute settlement process forward at each stage, they provided that, in future, consensus agreements would be required no to move. The effect would be to end the possibility of a country unilaterally blocking the dispute mechanism, and to build automaticity into the progress of a dispute through the system, unless all countries agreed that the process should be halted" ${ }^{38}$

36. Cf. Pierre Pescatore - Drafting and Analyzing Decisions on Dispute Settlement, cit., pp. 2830, 34-5.

37. Cf. Christopher Thomas, Litigation Process under the GATT dispute settlement system: lessons for the World Trade Organization, in Journal of World Trade, v. 30, n. 2 (april 1996), pp. 5381 .

38. Cf. John Croome, Reshaping the World Trading System, cit., p. 324. 
Isto configurou um efetivo direito a um panel (DSU art. $6^{\circ}, \S 1^{\circ}$ ); um direito à adoção de um panel report (DSU art. $16, \S 4^{\circ}$ ), um direito de recorrer de um panel report ao Órgão de Apelação (DSU - art. 16, § $4^{\circ}$ ) e um direito de adoção do "Report do Appellate Body" (DSU art. 17, § 14).

(iv) Também em matéria de adensamento de "juridicidade" do sistema cabe referir a uma outra e fundamental inovação: a criação de uma segunda instância, incumbida de rever, com base no direito, panel reports. Esta hipótese, que começou a ser discutida e negociada na Rodada Uruguai a partir de $1989,{ }^{39}$ foi consagrada no DSU, que contemplou um Standing Appellate Body. Este é composed of seven members, three of whom shall serve on any one casy $\left(17, \S 1^{\circ}\right)$, eleitos por um mandato de quatro anos, permitida uma reeleição $\left(17, \S 2^{\circ}\right)$, e integrado por persons of recognized authority, with demonstrated expertise in law, international trade and the subject-matter of the covered agreements generally (DSU 17, $\S 3^{\circ}$ ). Como o appeal shall be limited to issues of law covered in the panel reports and legal interpretations developed by the panel $(17, \S 6)$ esta segunda instância - quase única no âmbito do Direito Internacional Público - reforça, pela sua função, o componente da juridicidade do sistema de solução de controvérsias da OMC.

O Órgão de Apelação já foi constituído, elaborou o seu regimento interno (working procedures) e pronunciou-se sobre um caso "United States Standards for Reformulated and Conventional Gasoline complaint by Venezuela and Brasil" O report do Órgão de Apelação foi adotado pelo Órgão de Solução de Controvérsias em 20 de maio de 1996 e está agora na fase de implementação.

Em matéria dos working procedures do Appellate Body, observo apenas dois pontos: (a) o Órgão de Apelação foi constituído com base no standard de que é broadly representative of the WTO membership e que, sendo comparável a um standing tribunal, a nacionalidade não é um fator na seleção - e por tabela na exclusão - de qualquer membro to sit on a division to hear a particular case (Rule 6, $\S 2$ of the Working Procedures for Appelate Review). Neste sentido, a segunda instância é distinta das regras de constituição do panel, enquanto uma primeira instância (DSU 8, § 3), na qual a nacionalidade das partes envolvidas é vista como uma presunção de parcialidade; (b) os working procedures preservando a responsabilidade plena da câmara de três (division) quanto à decisão tomada, contempla informação e consulta a todos os membros do Appellate Body, sobre os

39. Cf. John Croome, Reshaping the World Trading System, cit., p. 264. 
casos em andamento, por força da regra que criou, da colegialidade. A idéia da colegialidade exprime uma preocupação de natureza jurídica, com a coerência da interpretação do ordenamento jurídico da OMC (Rule 4, Working Procedures for Appelate Review), o que é outro ingrediente do adensamento de juridicidade.

Não me cabe, e não é apropriado, no momento, na minha dupla condição de Embaixador do Brasil junto à $\mathrm{OMC}$ e presidente de seu Órgão de Solução de Controvérsias, fazer comentários sobre o primeiro report do Appellate Body, e a sua relação com o report do Panel, que deram ganho de causa ao pleito da Venezuela e do Brasil. Também de um caso não é razoável extrair ilações sobre tendências. Entretanto, não seria despropositado observar que há uma diferença de estilo neste primeiro report do Appellate Body, quando comparado com os reports de panels. É visivelmente um texto de cunho mais jurídico e, sem deixar de ser "persuasivo" está mais próximo da linguagem de um "prescriptive document" ou seja, do estilo de uma sentença jurídica.

(v) Estilo e automaticidades, acima examinados e comentados, não-convertem os reports dos panels e do Appellate Body em sentenças judiciais. Com efeito, os reports só adquirem plenitude de efeitos jurídicos, quando aprovados pelos Estadosmembros, através de um órgão criado pela constituição da OMC o "Dispute Settlement Body" o Órgão de Solução de Controvérsias que é o Conselho Geral, operando to "discharge the responsabilities", "provided for in the Dispute Settlement Understanding" (Acordo de Marrakesh art. IV. § 3, DSU-2, § $1^{\circ}$ ). Esta aprovação, ainda que tenha o potencial de automaticidade, é o que configura o "exequatur", através de uma homologação política, por via de regra, do consenso negativo.

Por esta razão é que entendo que os reports continuam tendo, no sistema da OMC, formalmente, a natureza jurídica de um parecer, de um tertius, acima das partes, dotado de vis directiva. A mudança o desenvolvimento progressivo reside no adensamento da juridicidade tanto do due process quanto da conversão do seu produto, os pareceres, em findings, dotados de eficácia jurídica.

O que quero dizer com a expressão "adensamento de juridicidade"? 
A obra de Hart instigou a teoria geral do direito a trabalhar com a distinção normas primárias/normas secundárias e a ver no crescente interrelacionamento entre ambas o sinal de maturidade de um sistema jurídico. ${ }^{40}$

Normas primárias são as que prescrevem, proscrevem, estimulam ou desestimulam comportamentos. No caso da OMC, seus destinatários são os Estadosmembros, cuja discricionariedade na sua observância e aplicação se vê contida pela existência de normas secundárias. Normas secundárias são normas sobre normas. Tratam da produção e da aplicação de normas. O sistema da solução de controvérsias da OMC adensou a sua juridicidade, reduzindo a sua dimensão diplomática - caracterizada pelo controle político dos Estados-membros no encaminhamento das soluções - através da multiplicação das normas secundárias que regem a organização e o funcionamento do sistema. São exemplos do papel das normas secundárias, para a identificação do quid sit juris, na OMC, aquelas que atribuem competências e poderes ao tertius (Panels e Appellate Body). Menciono, a título de ilustração de sua importância, para o adensamento da juridicidade, além das já-referidas - competência dada pelos standard terms of reference, e a regra do consenso negativo no DSU, - as seguintes: art. 9 (procedures for multiple complaints); art. 12 (panel procedures e o apêndice 3 do DSU que contempla, inter alia, strict time frames for every step of the process); art. 13 (right to seek information); art. 14 (confidentiality); art. 17 (intern review of stage); os workingprocedures do Appellate Body, cuja produção foi delegada ao próprio Appellate Body, em consonância com os standards elaborados no art. 17, §§ 9, 10, 11, 12, 13 do DSU; o art. 20 - (time-frame for DSB decisions), etc.

(vi) A juridicidade e o due process dos panels e do Appellate Body inserem-se num contexto mais amplo, de natureza diplomática: o Dispute Settlement Body - o Órgão de Solução de Controvérsias. Este, em contraste com o sistema do GATT, como já foi dito, representa uma especialização funcional do Conselho Geral. Esta especialização funcional dá ao OSC uma identidade institucional própria, reveladora da hierarquia e da importância atribuída pela OMC à solução de controvérsias, como elemento central da security and predictability do multilateral trading system, negociado na Rodada Uruguai (DSU, 3, §2).

40. Cf. H. L. A. Hart, The Concept of Law, New York, Oxford University Press, 1961, cap. V, VI; Norberto Bobbio - Contributi ad un dizionario giuridico, Torino, Giappichelli, 1994, cap. XI norma giuridica, cap. XII - norma secondaria. 
Ao OSC cabe a gestão de todo o sistema. É ele, como foi visto, que tem autoridade para estabelecer panels e adotar os seus reports assim como os do Appellate Body. É ao OSC, como órgão diplomático, que cabe ex-officio "maintain surveillance of implementation of ruling and recommendations". É ao OSC que também compete authorize suspension of concessions and other obligations under the covered agreements (DSU, art. 2, $\left.\S 1^{\circ}\right)$. Em outras palavras, se o processo de conhecimento passa pelo iter dos panels e do Appellate Body, o processo de execução dos findings transita, ainda que disciplinado por normas secundárias de surveillance of implementation (DSU art. 21) e de compensation and suspension of concessions (DSU, art. 22) (ou seja, sanções) por um órgão político-diplomático - o OSC.

$\mathrm{O}$ processo de execução, na sistemática da $\mathrm{OMC}$, tem duas fases. A primeira diz respeito ao monitoramento da efetivação das decisões dos panels e do Órgão de Apelação, adotadas pelo Órgão de Solução de Controvérsias. O mecanismo de monitoramento está previsto no art. 21 do DSU, que objetiva prompt compliance com as recommendations and rulings. $\mathrm{O}$ cumprimento do estabelecido pelos reports adotados pelo OSC é visto como algo do interesse de todos os Estadosmembros da OMC (DSU art. 21, $\S 1^{\circ}$ ). Assim, dentro de trinta dias da adoção de um report pelo OSC, o Estado-membro vencido deve informar ao OSC as suas intenções quanto à implementação das recommendations and rulings (DSU, art. 21, $\S 3$ ). Na hipótese de o cumprimento imediato ser impraticável, prevê-se um período razoável de tempo. O reasonable period of time é um standard, e como todo standard uma norma de conteúdo variável. No caso, representa buscar um comportamento razoável para os destinatários do report, ou seja, um equilíbrio entre direitos e interesses divergentes de um Estado-membro reclamante e um Estadomembro reclamado.

Os critérios para a busca deste equilíbrio são dados pelas normas secundárias do art. $21, \S 3$, que estabelece três métodos seqüenciais para determinar o reasonable period of time para a implementação. $\mathrm{O}$ art. $21, \S 3$ (a) estabelece que o prazo razoável pode ser o proposto pelo Estado-membro vencido desde que o prazo proposto seja aprovado pelo OSC. O art. $21, \S 3$ (b) estipula que o prazo pode ser o estabelecido por mútuo acordo entre reclamante e reclamado, dentro de 45 dias da adoção, pelo OSC, das recommendations and rulings do report. $\mathrm{Na}$ inexistência de acordo, o art. $21, \S 3$ (c) prevê uma arbitragem vinculante e obrigatória, cujo objetivo é o de determinar, no caso concreto, o reasonable period of time para a 
implementação. A indicação do árbitro ou árbitros, pode resultar de mútuo acordo entre as partes concernidas, dentro do prazo de dez dias, a partir do momento em que o assunto for remetido à arbitragem. Se as partes não conseguirem chegar a um acordo, o Diretor-Geral da OMC designará o árbitro depois de consulta às partes. (Notas de rodapé 12 e 13 ao artigo $21, \S 3$ (c) do DSU).

$\mathrm{O}$ art. 21 também estabelece diretrizes para a arbitragem do "prazo razoável" Este prazo não deve ultrapassar quinze meses da adoção do report, do panel ou do Órgão de Apelação, pelo Órgão de Solução de Controvérsias. Pode, no entanto, ser maior ou menor, dependendo das "circunstâncias particulares" (DSU art. $21, \S 3$ (c)). São, portanto, estas particular circunstances que os árbitros deverão examinar, que constituem, assim, a latitude in concreto, da apreciação do conteúdo variável da norma, para se encontrar, através de um tertius, uma solução razoável.

$\mathrm{O}$ art. $21, \S 5$ do DSU exprime igualmente uma preocupação no sentido da implementação ser consistente com os covered agreements. Ainda que dúvidas quanto a esta consistência só ensejam novos recursos ao mecanismo de solução de controvérsias de preferência ao panel original -, pelos Estados-membros partes da controvérsia, esta preocupação, juridicamente tutelada, indica a presença do valor atribuído à manutenção da integridade do ordenamento jurídico da OMC.

$\mathrm{Na}$ hipótese de não-cumprimento, o DSU estabelece um mecanismo de sanções que é, assim, a segunda fase do processo de execução.

As sanções previstas que como todas sanções constituem um expediente para reforçar o cumprimento das normas primárias são as típicas do Direito Internacional Público de Cooperação. ${ }^{41}$ Visam atingir o Estado-membro inadimplente, reduzindo os benefícios que este Estado tem de participar numa interdependência econômica, concebida grocianamente.

A aplicação destas sanções, mesmo através do OSC, enquanto órgão político-diplomático, é rule-oriented. Com efeito, o DSU tem, neste sentido, como objetivo explícito conter o unilateralismo do self-help. Contempla o redress of a violation of objectives or other nullification or impairment of benefits unicamente pelo iter das normas secundárias das rules and procedures do Understanding (DSU art. 23). A escolha das concessões a serem suspendidas, o setor de bens e serviços a ser afetado, o seu nível, são objeto dos standards elaborados no art. 22 do DSU.

41. Cf. Wolfgang Friedmann, The Changing Structure of International Law, New York, Columbia University Press, 1964, pp. 88-95. 
Objeções quanto à aplicação dos standards ensejam a possibilidade de uma arbitragem a ser conduzida pelo panel originário if members are available or by an arbitrator appointed by the Director-General, cuja competência está fixada no DSU (DSU - art. 223, § 6, § 7), não-requerendo, assim, um "compromis"

Estas observações são igualmente relevantes na perspectiva do adensamento da juridicidade do processo de execução. Com efeito, o self-help unilateral, por ser discricionário, tende à violência que se caracteriza, inter alia, pela imprevisibilidade, pela descontinuidade, pela desproporção entre meios e fins. As normas secundárias do DSU são multilateralmente disciplinadoras do uso da força econômica. Impõem medida à violência e estabelecem, como standards para o OSC, agir com medida; de acordo com a medida, e tendo como fim a medida. ${ }^{42}$

(vii) $\mathrm{O}$ adensamento da juridicidade, que estou realçando, não exclui, muito pelo contrário, o papel do OSC como instância política diplomática de solução de controvérsias no âmbito da OMC. Esta é parte importante de suas funções como gestora do DSU. Ela se evidencia, formalmente, no DSU, pela cautela recomendada before bringing a case; pela preferência explícita por soluções negociadas (DSU, art. $3, \S 7$ ); pela recomendação de que a interpretação das normas da OMC deve ser estrita e não construtivamente ampliada (DSU 3, § 2) e especialmente pela obrigação de consultar, como fase prévia obrigatória, antes de suscitar-se a constituição de um panel (DSU, art. 4).

Em matéria de obrigação de consultar, cabe reiterar a sua importância no encaminhamento dos contenciosos econômicos e especificar o que já foi apontado, a saber que o sistema da OMC, contrastando com o do GATT, adensou a juridicidade do processo de consultas previsto no art. XXII, através de normas secundárias que disciplinam a sua automaticidade e obrigatoriedade e fixam prazos para a sua realização. O regime geral contemplado pelo DSU é o de uma resposta dentro de dez dias do pedido de consulta para a sua realização em período de até trinta dias após a data do recebimento do pedido de consulta, devidamente notificado ao OSC. O não-cumprimento destes prazos, salvo por mútuo acordo, autoriza o membro-reclamante a pedir a constituição de panel (DSU, art. 4, § $3, \S 4$ ). O período de sessenta dias, após o pedido de consulta, é o definido como um standard de tempo apropriado, para se chegar a uma solução negociada, em consonância com os covered agreements. Este é o iter preferencial, recomendado pelo DSU. Inexistindo

42. Cf. Norberto Bobbio - Il terzo assente, cit., pp. 151-2. 
solução, faculta-se ao reclamante requerer a constituição de um panel. Dentro da lógica da jurisprudência diplomática, o período de consultas pode ser estendido, havendo mútuo acordo das partes envolvidas.

Nesta linha de contribuir para uma solução negociada, também merece registro a possibilidade de, alternativamente, recorrerem as partes, numa disputa, desde que de comum acordo, aos bons ofícios, à conciliação e à mediação, facultando-se ao Diretor-Geral, ex-officio, a possibilidade de oferecer-se para bons ofícios, conciliação ou mediação (DSU, art. 5).

Outro dado importante, a indicar a preservação da tradição gattiana de jurisprudência diplomática, é a possibilidade de se suspender, a qualquer momento, os trabalhos de um panel com vistas a se negociar uma solução. Num caso recente European Communities Trade Description of Scallops, complaints by Canada, Peru and Chile - as partes solicitaram a não-circulação do report de que tinham conhecimento, justamente para negociar uma solução em função dele. Uma solução negociada para este caso foi comunicada ao OSC, na sua sessão de 5 de julho de 1996. Esta mesma possibilidade existe na segunda instância (cf. Working Procedures for Appellate Review, Rule 30). Isto, diga-se de passagem, é outro elemento para sustentar minha afirmação de que os reports não são sentenças, mas pareceres com vis directiva, com um iter jurídico que pode ser interrompido a qualquer momento, para se tentar uma solução diplomaticamente negociada.

A dimensão política diplomática do Órgão de Solução de Controvérsias no encaminhamento de controvérsias pode igualmente ser apontada pelo direito de, no processo de automaticidade da adoção do report do panel e do Appellate Body, qualquer membro express their view quanto ao seu conteúdo (DSU, $16, \S 4 ; 17, \S 4)$. Este direito foi exercido pelo Japão, na sessão do OSC que adotou o report do Appellate Body no caso da gasolina. Naquela ocasião, o Japão reservou seus direitos quanto à interpretação contida no report sobre o art. III:4 do GATT. O exercício deste direito representa a possibilidade de um controle político no sentido de fiscalização do conteúdo jurídico de um report. Este artigo tem como objetivo, no meu entender, ressalvar direitos e deixar claro que os findings aplicam-se apenas "to the matter at issues and the parties involved in a particular case". ou seja, obstruir o conceito do precedente obrigatório stare decisis.

Um balanço das atividades do OSC da OMC até o presente momento é indicativo de que ele vem funcionando no trato dos contenciosos, ora para instigar soluções negociadas, ora para promover soluções de natureza mais jurídica. Existem 
dez casos que foram solucionados via negociação ou na fase das consultas ou depois do pedido de panel. Entre eles, o mais rumoroso foi o United States Imposition of Import Duties on Automobiles from Japan under section 301 and 304 of the Trade Act of 1974 - complaint by Japan.

Existem seis Active Panels e vinte e seis consultas em andamento. $\mathrm{O}$ caso já-mencionado, United States Standards for Reformulated and Conventional Gasoline, complaints by Venezuela and Brazil é o único que percorreu todas as etapas do processo de conhecimento, do Panel ao Appellate Body, e está na fase de implementação (processo de execução).

$\mathrm{O}$ uso do OSC, ratione personae, tem sido variado, pois vem sendo suscitado por países desenvolvidos e por países em desenvolvimento, em contenciosos que envolvem controvérsias entre membros desenvolvidos, membros em desenvolvimento e membros desenvolvidos e em desenvolvimento.

(viii) Para concluir, gostaria de fazer uma indicação, ainda que rápida, sobre a natureza do contencioso da OMC, posto que ela permite uma referência a um tema central dos trabalhos da CDI: o da responsabilidade internacional.

A tradição do GATT, o seu foco em nullification and impairments of benefits, a gravitação do tema de uma "jurisprudência diplomática", tende a ver, no atual sistema da OMC, um contencioso juridicamente adensado de reparação de interesses. A conseqüência é configurar o não-cumprimento de uma obrigação internacional - por exemplo a implementation de rulings and findings de reports adotados pelo DSB - como uma hipótese de responsabilidade internacional que diz respeito apenas à relação entre as partes diretamente envolvidas no panel. Por via de conseqüência, a função da reparação pode ser resolvida pelos mecanismos tradicionais da responsabilidade internacional, ou seja, por compensação (dommages-interêts). O art. 22 do DSU, ainda que não a prefira, admite a negociação de compensation, ressalvando que deve ser "consistent with the covered agreements". Aliás, a preocupação de consistência com os covered agreements existe também para as soluções negociadas de qualquer tipo. Daí a obrigação de notificá-las ao OSC e a possibilidade de qualquer membro raise any point relating thereto (DSU 3, § 6).

Esta preocupação com a consistência: the first objective of the dispute settlement mechanisms is usually to secure the withdrawal of the measures concerced if these are founde to be inconsistent with the provisions of any of the covered agreements (DSU 3, § 7); ...neither compensation nor the suspension of 
concessions or other obbligations is prefered to full implementation of a recommendation to bring a measure into conformity with the covered agreement $\left(D S U 22, \S 1^{\circ}\right)$ - suscita uma outra questão. A saber, se o novo sistema de solução da OMC, em contraste com o do GATT, não tende para um contencioso de legalidade. Isto significa, potencialmente, uma outra concepção da função da responsabilidade internacional, qual seja a função de proteção de legalidade, o que quer dizer que a relação da responsabilidade internacional transcenderia as partes envolvidas numa disputa pois diria respeito, igualmente, a todos os membros da OMC. Com efeito, se a responsabilidade internacional é uma resposta a uma ruptura do equilíbrio de direitos e obrigações, e se a resposta exclui como remédio a obrigação de reparar através de compensação - negociada entre as partes diretamente envolvidas por força de uma prioridade axiológica conferida ao interesse de todos os Estadosmembros na função da legalidade, estaríamos aí diante de uma diversificação muito ampliada de responsabilidade internacional na linha de propostas dos trabalhos da CDI. $^{43}$

$\mathrm{Na} \mathrm{OMC}$, este assunto - contencioso de reparação/contencioso de legalidade - vem sendo suscitado, implicitamente, através do papel das third parties. Com efeito, se para a participação na fase prévia de consultas de uma controvérsia o DSU requer para a participação de terceiros, a existência de um substantial trade interest, a participação de third parties, tanto num panel quanto num appeal, pressupõe substantial interest (DSU 10, § 2;17, §4). A pergunta é se por substantial interest pode se entender systemic interests o que, no jargão da OMC, pode ser entendido como um interesse também na função da legalidade da responsabilidade internacional. Em outras palavras, se o panel e o Appellate Body no trato que devem dar às considerações de terceiros precisam dar atenção - e quanto - a estes systemic interests. Não há dúvida que numa disputa só nullification and impairment of benefits permite um terceiro transformar sua intervenção num pleito a traduzir-se em direito a um panel (DSU, art. 10, § 4) e que também só as partes, e não-terceiros, têm o direito de appeal a panel report (DSU, 17, § 4). Em outras palavras, o prejuízo indireto, derivado do interesse sistêmico na função da legalidade, não dá a um Estado-membro o direito de exercer o papel de ministério

43. Cf. Société Française pour le Droit International, La Responsabilité dans le Système International, Colloque de Mans (1990) Paris, Pedone, 1991, particularmente Pierre-Marie Dupuy, Responsabilité et Légalité, pp. 263-297; e Brigitte Stern, La Responsabilité dans le Système International, pp. 319-336. 
público na defesa de um interesse coletivo na manutenção de coerência do ordenamento jurídico da OMC. Neste sentido, diria, para recorrer ao que afirmou a Corte Internacional de Justiça em 1966, no caso South West Africa and Namibia, que não se admite uma espécie de actio popularis, - um direito, para cada Estadomembro da OMC intentar uma ação para a defesa do interesse público. ${ }^{44}$

Estes problemas, de maior ou menor amplitude da responsabilidade internacional estão, no entanto, ainda em aberto, por força de algumas intervenções de terceiros, que aguardam pronunciamento e decisões. É, portanto, uma questão para a qual se deve aguardar as tendências que se consolidarão, ou-não, na jurisprudência futura da OMC.

44. Cf. Dominique Carreau, Droit International, $3^{\text {a }}$ ed., Pedone, 1991, p. 429; Brigitte BoleckerStern, Le Préjudice dans la Résponsabilité Internationale, Paris, Pedone, 1972. 